\title{
American bison Bison bison wallowing behavior and wallow formation on tallgrass prairie
}

\author{
Bryan R. COPPEDGE* and James H. SHAW
}

\begin{abstract}
Coppedge B. R. and Shaw J. H. 2000. American bison Bison bison wallowing behavior and wallow formation on tallgrass prairie. Acta Theriologica 45: 103-110.

We characterized social and spatial patterns of wallowing (dust-bathing) behavior in an American bison Bison bison (Linnaeus, 1758) population on a tallgrass prairie site in Oklahoma, USA. Consistent with earlier studies, wallowing was primarily practiced by adults. Unlike earlier studies, however, aggressive interactions associated with wallowing incidents were rare, probably due to the reduced bull:cow ratio in the population. Forty-three significant soil disturbance sites, known as wallows, were created by wallowing activity during the 2-year study. The spatial distribution of wallows was significantly different from overall bison habitat use patterns for some landscape characteristics. Bison preferentially formed wallows on relatively level areas on spring and fall burns, thus avoiding summer burns, unburned areas, and severe slopes. Bison wallowed exclusively on bare or exposed soils when not using wallows, and in many instances wallowed on soil disturbed by other animals. When coupled with a preference for wallowing on relatively coarse soils, bison clearly exhibit a macro- and microsite preference for the conduction of this behavior. This preference has important implications for wallow distribution and their resulting ecological function in prairie environments.
\end{abstract}

Oklahoma Cooperative Fish and Wildlife Research Unit, Department of Zoology, Oklahoma State University, Stillwater, Oklahoma 74078, USA

Key words: Bison bison, soil disturbance, grassland fire, topography, GIS

\section{Introduction}

One of the most conspicuous behaviors of American bison Bison bison (Linnaeus, 1758 ) is their dust-bathing or 'wallowing' in loose soil (McHugh 1958). Wallowing is both an aggressive behavior exhibited by competing bulls during the summer rut (McHugh 1958, Lott 1974) and a grooming activity (Reinhardt 1985, Mooring and Samuel 1998). Reinhardts' (1985) quantitative study on seasonal and social patterns of wallowing behavior found that wallowing increased substantially during summer and was practiced mostly by adult animals with higher social ranking. However, that study was conducted on a small herd ( $<25$ animals) under confined conditions ( 40 ha enclosure). A similar study of wallowing behavior

\footnotetext{
* Address for correspondence: Dept. of Plant and Soil Sciences, 368 AGH, OSU, Stillwater, OK 74078, USA
} 
patterns in a less-confined bison population is needed because such a population is more likely to possess the natural and historic socioecological conditions under which this behavior developed (Lott 1991).

An understanding of spatial characteristics that influence this behavior is also important because frequent, repeated wallowing by bison on the same site often forms characteristic soil depressions called wallows. Wallows were once a distinctive feature of North American prairies (England and DeVos 1969), and are important components of prairie ecosystems as they provide soil disturbance sites that increase plant and habitat diversity (Collins and Barber 1985, Umbanhowar 1992). This leads to questions as to how bison select sites for wallow formation. Are certain topographic or habitat features selected by bison for wallow formation, or are wallowing sites randomly selected as a simple function of habitat use patterns?

We evaluated bison wallowing behavior and wallow formation when the Nature Conservancy established the 15,342-ha Tallgrass Prairie Preserve in Oklahoma, USA. As part of a restoration effort, bison were reintroduced to the area after an absence of almost 140 years (Shaw and Lee 1997). Our objectives were to quantify wallowing activity in this population and spatially characterize sites used by bison for wallow formation. Specifically, we evaluated the following predictions. First, consistent with earlier studies (McHugh 1958, Reinhardt 1985), we hypothesized wallowing activity would be primarily an adult behavior accompanied by aggressive interactions. Second, we hypothesized that wallow formation sites would be chosen randomly; thus, the spatial distribution of wallows in relation to various landscape features should not differ from general patterns of bison habitat use.

\section{Study site and methods}

The Tallgrass Prairie Preserve (TPP) is located $25 \mathrm{~km}$ northwest of Pawhuska in northern Oklahoma, USA ( $36^{\circ} 50^{\prime} \mathrm{N}, 96^{\circ} 25^{\prime} \mathrm{W}$ ). The TPP is situated in the Osage Hills, an area characterized by hilly topography and rocky soils that historically prevented extensive cultivation. Vegetation of the TPP is native tallgrass prairie. Prior to its establishment in 1989, the TPP was grazed by cattle and spring-burned every 1-2 years. It was never plowed. Current management practices include prescribed burning $20 \%$ of the preserve annually with spring, summer, and fall burns (Hamilton 1996).

Three hundred bison were reintroduced into a 1,973-ha part of the TPP in October 1993. Due to natural recruitment and additions to the herd, the size of the study population grew during the study from 300 to 420 animals. Herd management was limited to annual roundups for inoculations and age/sex class structure adjustment. Herd composition during the study averaged $7 \%$ bulls (males $>2$ yrs of age), $51 \%$ cows (females $>2$ yrs of age), $22 \%$ yearlings (all animals $1 \mathrm{yr}$ of age), and $20 \%$ calves (all animals $<1$ yr of age).

In conjunction with a study of bison-fire interactions (Coppedge and Shaw 1998), the study area was surveyed 4 to 12 times per month during daylight hours to assess bison habitat use. The location, size, and composition of all groups of animals were noted and mapped on 1:24,000 USGS topographic quadrangles with the aid of 1:7920 aerial photographs. To assess social patterns in wallowing behavior, we observed wallowing activity on randomly chosen groups during 1 to 3 hour observation periods from November 1993 to October 1995. Wallowing, as defined by Reinhardt (1985), was the act of an animal lying laterally on the ground rolling towards its dorsum. Data recorded during observations included the substrate animals used for wallowing, categorized as either undisturbed (vegetated) 
ground, bare soil, disturbed soil such as mammal diggings or ant mounds, or new wallows; age/sex class of the animal performing the behavior; and any aggressive interactions with other herd members that accompanied the behavior. These interactions included bunts, lunges, auditory threats and displacements (Rothstein and Griswold 1991). Social patterns of wallowing activity were analyzed by pooling all observations by age/sex class and testing against the expected distribution based on population proportions with $\chi^{2}$ analysis. To test whether all classes were represented equally in observations, we tested observed frequencies of each age/sex class against population proportions; as there was no difference in observed vs. population proportions $\left(\chi^{2}=1.12, p>0.25\right)$, we were assured that all classes were appropriately represented in the sampling effort.

To assess characteristics of sites used by bison for wallowing and wallow formation, the study area was surveyed prior to reintroduction in 1993 by conducting $2001-\mathrm{km}$ by $10-\mathrm{m}$ belt transects across the study area on foot or on all-terrain vehicle when possible. The purpose of this preliminary survey was to locate and map any existing soil anomalies and depressions that might be confused at a later date with newly formed bison wallows. The area was resurveyed bi-monthly during the study and again in late October 1995 to locate new wallows formed by bison. Wallow locations were mapped on 1:24,000 USGS topographic quadrangles with the aid of 1:7920 aerial photographs. To assess both habitat use by bison and the spatial distribution of wallows, bison group and wallow locations were digitized into a geographic information system (GIS). Landscape variables of interest in assessing spatial patterns of habitat use and wallow distribution were elevation, prescribed burn history, slope, and aspect. Seasonal burns were digitized from existing topographic quadrangles and grouped into classes according to the date they were conducted: spring (March-April), summer (September), fall (November-December), or areas unburned during the study. Using georegistered, digitized topographic quadrangles, we used the GIS to generate high ( $\geq 338 \mathrm{~m})$, middle (337-324 m), and low $(\leq 323 \mathrm{~m})$ elevation classes; slight (0-3\%), moderate $(4-7 \%)$, and severe $(8 \%)$ slope classes; and north $\left(315-45^{\circ}\right)$, east $\left(45-135^{\circ}\right)$, south $\left(135-225^{\circ}\right)$, and west $\left(225-315^{\circ}\right)$ slope aspect classes. Subsequent analysis within the GIS was conducted by overlaying and cross-tabulating digital maps of bison and wallow locations with the digital map of each landscape variable.

Because bison do not use the landscape randomly (Coppedge and Shaw 1998), it is not reasonable to expect animal-related effects such as wallows to exhibit random spatial distributions. Therefore, we calculated expected spatial distributions for wallows based on observed patterns of habitat use by bison. This approach allowed us to determine whether bison formed wallows randomly within used habitats or chose particular areas or certain landscape features for the behavior. Statistical analyses included tests for differences in observed and expected distribution of wallowing activity by age/sex class and tests on spatial distribution of wallows relative to bison habitat use patterns for landscape characteristics. Selectivity for certain landscape features was assessed by calculating $95 \%$ Bonferroni confidence intervals following significant $\chi^{2}$ analysis (Neu et al. 1974, Byers et al. 1984).

\section{Results}

A total of 170 wallowing incidents were observed in 331 hours of observation. Wallowing occurred either on bare soil ( $60 \%$ of observations), disturbed soil (15\%), or in new wallows $(25 \%)$. Only 5 incidents (3\% of total) were observed in which aggressive behavior accompanied wallowing. In each instance, a young subordinate cow was displaced from a wallow by an older, more dominant cow. Most observations $(89 \%)$ of wallowing were limited to adult animals (bulls and cows), which comprised only $58 \%$ of the population. Thus, wallowing was not distributed proportional to the age/sex class structure of the population $\left(\chi^{2}=52.9, p<0.001\right)$. Bulls and cows wallowed more than expected, while yearlings and calves wallowed much less frequently (Table 1). 
Table 1. Social distribution of bison wallowing observations on the Tallgrass Prairie Preserve in Oklahoma, 1993-1995. Expected distributions were based on the respective age-sex class proportions of the study population. Statistical differences in observed vs. expected number of observations were determined by calculating 95\% Bonferroni confidence intervals following $\chi^{2}$ analysis (Byers et al. 1984). "+" - more than expected, 0 - no difference, "-" - less than expected.

\begin{tabular}{lcccc}
\hline & Population & \multicolumn{2}{c}{ Wallowing observations } & Statistical \\
\cline { 3 - 4 } Age/sex class & proportion & No. observed & No. expected & differences \\
\hline Bulls & 0.07 & 35 & 12 & + \\
Cows & 0.51 & 116 & 87 & + \\
Yearlings & 0.22 & 16 & 37 & - \\
Calves & 0.20 & 3 & 34 & - \\
\hline
\end{tabular}

Table 2. Spatial distribution of bison wallows on the Tallgrass Prairie Preserve in Oklahoma relative to landscape characteristics. Expected distributions were determined from habitat availability based on observed patterns of bison habitat use. Significant site selectivity was determined by calculating $95 \%$ Bonferroni confidence intervals following $\chi^{2}$ analysis (Byers et al. 1984). "+" - preferred, 0 - no preference, "-" - avoided.

\begin{tabular}{|c|c|c|c|}
\hline \multirow{2}{*}{$\begin{array}{l}\text { Landscape } \\
\text { characteristic }\end{array}$} & \multicolumn{2}{|c|}{ Wallow distribution } & \multirow{2}{*}{ Selectivity } \\
\hline & No. observed & No. expected & \\
\hline \multicolumn{4}{|l|}{ Burns } \\
\hline Spring & 17 & 8 & + \\
\hline Summer & 3 & 10 & - \\
\hline Fall & 23 & 12 & + \\
\hline Unburned & 0 & 13 & - \\
\hline \multicolumn{4}{|l|}{ Elevation } \\
\hline High ( $\geq 338 \mathrm{~m})$ & 24 & 19 & 0 \\
\hline Middle (337-324m) & 3 & 12 & - \\
\hline Low $(\leq 323 \mathrm{~m})$ & 16 & 12 & 0 \\
\hline \multicolumn{4}{|l|}{ Slope } \\
\hline Slight $(0-3 \%)$ & 15 & 17 & 0 \\
\hline Moderate (4-7\%) & 27 & 17 & + \\
\hline Severe $(\geq 8 \%)$ & 1 & 9 & - \\
\hline \multicolumn{4}{|l|}{ Aspect } \\
\hline North $\left(315-45^{\circ}\right)$ & 6 & 6 & 0 \\
\hline East $\left(45-135^{\circ}\right)$ & 15 & 14 & 0 \\
\hline South $\left(135-225^{\circ}\right)$ & 11 & 13 & 0 \\
\hline West $\left(225-315^{\circ}\right)$ & 11 & 10 & 0 \\
\hline
\end{tabular}


Bison formed 43 wallows during the study. Burn history influenced bison wallow formation and distribution $\left(\chi^{2}=38.1, p<0.001\right)$, as all new wallows were located on areas burned during the course of the study. Bison exhibited a clear preference for establishing wallows on spring and fall burns but avoided summer burns and unburned areas (Table 2). Wallow distribution was not random with respect to elevation $\left(\chi^{2}=9.4, p<0.01\right)$. Wallows were found less frequently than expected at middle elevations, but were distributed consistently with observed habitat use patterns for high and low sites (Table 2). Slope was also an important influence on wallow location $\left(\chi^{2}=13.2, p<0.005\right)$. Bison formed wallows proportionally on slight slopes, preferentially on moderate slopes, but avoided severe slopes (Table 2). The slope aspect, however, was an insignificant factor in wallow formation $\left(\chi^{2}=0.5, p>0.25\right)$.

\section{Discussion}

Previous studies reported an increase in bison wallowing activity during summer associated with insect harassment and rut (McHugh 1958, Lott 1974). A more recent study reported an increase in fall (October) wallowing activity in response to larval ticks (Mooring and Samuel 1998). Arthropod harassment of bison can be severe in some locations (Melton et al. 1989), although Reinhardt (1985) did not attribute wallowing activity to insect harassment. Unfortunately, we did not quantify insect harassment levels for our study population. But these widely varying results indicate that a more detailed assessment of factors underlying the wallowing behavior of bison is needed, especially comparisons between diverse locales with varying environmental regimes and arthropod faunas.

As compared to earlier findings (Reinhardt 1985) where 13\% of wallowing was accompanied by aggression, wallowing appears to be primarily a grooming or comfort behavior in our study population. It is probable that the sex structure of this particular bison herd preempted aggressive wallowing activity by bulls. The male:female ratio during the study was $1: 7$; thus, there may have been minimal competition for mating access which decreased the need for aggressive wallowing displays by bulls (Lott 1974). The aggression levels noted in the earlier studies are probably the result of the confined conditions of the study population (Reinhardt 1985) or the high number of mature bulls (Lott 1974). Our findings do support the hypothesis that wallowing is primarily an adult behavior, consistent with previous studies that noted an increase in wallowing behavior with an increase in age (McHugh 1958, Reinhardt 1985).

It is interesting to note that, despite the altered age and sex structure of this population, the wallowing behavior still occurred, we did observe some aggressive interactions between wallowing cows, and distinctive wallows were formed. Wallow distribution resulted from macrohabitat selection of bison, which was principally 
determined by prescribed burn history and topography. This is consistent with studies on bison grazing patterns, as bison preferentially graze burned areas over unburned areas (Vinton et al. 1993). Furthermore, spring and fall burns are highly preferred as grazing sites by this particular population (Coppedge and Shaw 1998). Recently burned areas also have the largest amounts of bare ground and exposed soil, microsite features that bison clearly prefer as wallowing locations (Bowyer et al. 1998). As elsewhere in the North American Great Plains (Coppock et al. 1983), we observed that bison were also attracted to soil disturbances for wallowing, which in our area were mostly coyote Canis latrans or badger Taxidea taxus diggings or ant mounds (Formicidae). A related study (Coppedge et al. 1999) has also documented distinct soil textural differences between new wallow interiors and exterior reference sites. Soils of wallow interiors were much coarser than those of nearby reference sites. Coarser soils are less easily compacted and thus more suited to dustbathing, which appears to be the non-aggressive grooming function of the behavior (McHugh 1958). Thus, the presence of small areas of exposed, relatively coarse soil, resulting either from removal of aboveground vegetation by burning or disturbance by other animals, appears to be an important microsite influence on bison wallowing behavior.

Because of soil compaction, abandoned wallows retain moisture and harbor vegetative communities different from that of surrounding prairie (Polley and Collins 1984). Because vegetation on upland sites generally becomes more stressed in drier periods than vegetation in moister lowlands (Abrams et al. 1986), moist abandoned wallows might provide a refugia for drought-intolerant species. Wallows also function as soil disturbances, which provide critical colonization sites for ruderal and ephemeral species within grassland vegetation matrices dominated by highly-competitive perennials (Collins and Uno 1983). Thus, wallows are an important grassland landscape feature that increase habitat heterogeneity (Polley and Wallace 1986, Knapp et al. 1999), which in turn increases local plant diversity (Collins and Barber 1985, Umbanhowar 1992).

Our study is the first to document specific landscape features selected by bison for the performance of wallowing behavior. Through wallowing and less apparent behavioral activities such as horning (Coppedge and Shaw 1997), bison are capable of significant alteration of prairie habitats. These behaviors, when coupled with the effects of grazing (Hartnett et al. 1996, Coppedge et al. 1998), also demonstrate the numerous ways in which bison can influence prairie structure and function (Risser 1990). In fact, bison activities serve as such an integral part of prairie ecosystem functioning that bison have recently been designated a keystone species in tallgrass prairie (Knapp et al. 1999).

Acknowledgments: This study was funded by grants from the Nature Conservancy and the Oklahoma Cooperative Fish and Wildlife Research Unit (U. S. Dept. of the Interior, Oklahoma Department of Wildlife Conservation, Wildlife Management Institute, and Oklahoma State University cooperating). We thank T. S. Carter, D. M. Engle and D. M. Leslie Jr for constructive comments on an earlier version of the manuscript. 


\section{References}

Abrams M. D., Knapp A. K. and Hulbert L. C. 1986. A ten-year record of aboveground biomass in a Kansas tallgrass prairie: effects of fire and topographic position. American Journal of Botany 73: 1509-1515.

Bowyer R. T., Manteca X. and Hoymork A. 1998. Scent marking in American bison: morphological and spatial characteristics of wallows and rubbed trees. [In: International symposium on bison ecology and management in North America. L. Irby and J. Knight, eds]. Montana State University, Bozeman: 81-91.

Byers C. R., Steinhorst R. K. and Krausman P. R. 1984. Clarification of a technique for analysis of utilization-availability data. Journal of Wildlife Management 48: 1050-1053.

Collins S. L. and Barber S. C. 1985. Effects of disturbance on diversity in mixed-grass prairie. Vegetatio 64: 87-94.

Collins S. L. and Uno G. E. 1983. The effect of early spring burning on vegetation in buffalo wallows. Bulletin of the Torrey Botanical Club 110: 474-481.

Coppedge B. R. and Shaw J. H. 1997. Effects of horning and rubbing behavior by bison (Bison bison) on woody vegetation in a tallgrass prairie landscape. American Midland Naturalist 138: 189-196.

Coppedge B. R. and Shaw J. H. 1998. Bison grazing patterns on seasonally burned tallgrass prairie. Journal of Range Management 51: 258-264.

Coppedge B. R., Engle D. M., Toepfer C. S. and Shaw J. H. 1998. Effects of seasonal fire, bison grazing, and climatic variation on tallgrass prairie vegetation. Plant Ecology 139: 235-246.

Coppedge B. R., Fuhlendorf S. D., Engle D. M., Carter B. J. and Shaw J. H. 1999. Grassland soil depressions: relict bison wallows or inherent landscape heterogeneity? American Midland Naturalist 142: 382-392.

Coppock D. L., Ellis J. E., Detling J. K. and M. I. Dyer. 1983. Plant-herbivore interactions in a North America mixed-grass prairie. II. Responses of bison to modification of vegetation by prairie dogs. Oecologia 56: 10-15.

England R. E. and DeVos A. 1969. Influence of animals on pristine conditions on the Canadian grasslands. Journal of Range Management 22: 87-94.

Hamilton R. G. 1996. Using fire and bison to restore a functional tallgrass prairie landscape. Transactions of the 61st North American Wildlife and Natural Resources Conference 61: 208-214.

Hartnett D. C., Hickman K. R. and Walter L. E. F. 1996. Effects of bison grazing, fire, and topography on floristic diversity in tallgrass prairie. Journal of Range Management 49: 413-420.

Knapp A. K., Blair J. M., Briggs J. M., Collins S. L., Hartnett D. C., Johnson L. C. and Towne E. G. 1999. The keystone role of bison in North American tallgrass prairie. Bioscience 49: 39-50.

Lott D. F. 1974. Sexual and aggressive behavior of adult male American bison (Bison bison). [In: The behaviour of ungulates and its relation to management. Vol. 1. V. Geist and F. Walther, eds]. IUCN Publications, Morges, Switzerland: 382-394.

Lott D. F. 1991. American bison socioecology. Applied Animal Behaviour Science 29: 135-145.

Melton D. A., Larter N. C., Gates C. C. and Virgil J. A. 1989. The influence of rut and environmental factors on the behaviour of wood bison. Acta Theriologica 34: 179-193.

McHugh T. 1958. Social behavior of the American Buffalo (Bison bison bison). Zoologica 43: 1-54.

Mooring M. S. and Samuel W. M. 1998. Tick defense strategies in bison: the role of grooming and hair coat. Behaviour 135: 693-718.

Neu C. W., Byers C. R. and Peek J. M. 1974. A technique for analysis of utilization-availability data. The Journal of Wildlife Management 38: 541-545.

Polley H. W. and Wallace L. L. 1986. The relationship of plant species heterogeneity to soil variation in buffalo wallows. Southwestern Naturalist 31: 493-501.

Polley H. W. and Collins S. L. 1984. Relationships of vegetation and environment in buffalo wallows. American Midland Naturalist 112: 178-186. 
Reinhardt V. 1985. Quantitative analysis of wallowing in a confined bison herd. Acta Theriologica 30: $149-156$.

Risser P. G. 1990. Landscape processes and the vegetation of the North American grassland. [In: Fire in North American Tallgrass Prairies. S. L. Collins and L. L. Wallace, eds]. University of Oklahoma Press, Norman: 133-146.

Rothstein A. and Griswold J. G. 1991. Age and sex preferences for social partners by juvenile bison bulls, Bison bison. Animal Behaviour 41: 227-237.

Shaw J. H. and Lee M. 1997. Relative abundance of bison, elk, and pronghorn on the southern plains, 1806-1857. Plains Anthropologist 42: 163-172.

Umbanhowar C. E. 1992. Abundance, vegetation, and environment of four patch types in a northern mixed prairie. Canadian Journal of Botany 70: 277-284

Vinton M. A., Hartnett D. C., Finck E. J. and Briggs J. M. 1993. Interactive effects of fire, bison (Bison bison) grazing and plant community composition in tallgrass prairie. American Midland Naturalist 129: $10-18$.

Received 19 April 1999, accepted 3 August 1999 